\title{
The impact of type 1 diabetes on the development of the craniofacial mineralised tissues (bones and teeth): literature review
}

\author{
R. Chałas' , O. Rudzka', I. Wójcik-Chęcińska', M. Vodanović \\ ${ }^{1}$ Department of Conservative Dentistry and Endodontics, Medical University of Lublin, Poland \\ 2Department of Dental Anthropology, School of Dental Medicine, University of Zagreb, Croatia
}

[Received: 20 September 2015; Accepted: 10 November 2015]

\begin{abstract}
Background: There are many reports on the impact of diabetes on periodontium as well as the state of organs in diabetics; however, there is little research on the impact of the disease on morphological and anatomical changes in the mineralised tissues like teeth and craniofacial bones. The aim of this study was to present a review of literature on morphological and anatomical changes of mineralised tissues in the course of type 1 diabetes.
\end{abstract}

Materials and methods: A review of PubMed database was made using the keywords: morphological changes, anatomical changes, enamel hypoplasia, type 1 diabetes, induced diabetes and the names of individual anatomical and morphological structures of the teeth.

Results: The analysis of experimental studies have shown that in induced type 1 diabetes in rats there is a substantial reduction in the thickness of the enamel and dentin, compared with the control group. The changes in the content of individual minerals in the tissues of the tooth have been shown - a decrease in the concentration of calcium and fluoride ions and an increase in the concentration of magnesium. In a study conducted on embryos of rats born of diabetic dams, defects were observed in enamel organ, which can cause delayed enamel hypoplasia. Literature analysis revealed morphological disorders also in some clinical cases of patients with type 1 diabetes.

Conclusions: Type 1 diabetes mellitus as a metabolic disorder may affect changes in the structure of mineralised tissues, thereby increasing their susceptibility to caries development and orthognathic disorders. (Folia Morphol 2016; 75, 3: 275-280)

Key words: diabetes type 1 , tooth morphology, mineralised tissues

\section{INTRODUCTION}

Human teeth develop from ectoderm and mesoderm, and the deciduous teeth begin to develop in the $7-8^{\text {th }}$ week of gestation, while the permanent teeth buds are formed between $20^{\text {th }}$ week of gestation (first molars) and 5 years of age (third molars). Amelogenesis and histogenesis of deciduous teeth dentin begin in the $14-18^{\text {th }}$ week of gestation, and the beginning of the formation of the enamel and dentin of the first permanent molars is in the $28-32^{\text {nd }}$ week of gestation [18].

Several factors can affect the development of the dentition, including inter alia genetically determined disorders, calcium-phosphate disorders, hypo- or hy-

Address for correspondence: Dr hab. n. med. R. Chałas, Department of Conservative Dentistry and Endodontics, Medical University of Lublin, Poland, ul. Karmelicka 7, 20-081 Lublin, Poland, tel: +48 81528 7940, e-mail: renata.chalas@umlub.pl 
pervitaminosis, metabolic disorders, allergies, febrile illnesses, immunological diseases, specific and non-specific inflammations, endocrinopathies (including diabetes mellitus), abnormal blood pressure, postradiation injuries, disorders associated with maternity (the number of pregnancies, the age of a pregnant woman, pathological changes of the uterus), and drugs. These factors may act both during pregnancy (in utero) and in neonatal and postnatal period [18].

Diabetes is a metabolic disorder of complex aetiology, characterised by chronic hyperglycaemia resulting from a defect in insulin secretion or action, or both of these processes simultaneously. Chronic hyperglycaemia is associated with the dysfunction of, damage to and failure of various organs, particularly eyes, nerves, the heart and blood vessels. Type 1 diabetes (insulin-dependent) is less frequent than type 2 diabetes and accounts for $5-15 \%$ of all cases of diabetes [30]. Usually it develops in young people, when the development of deciduous and permanent teeth takes place. In type 1 diabetes, the pancreas secretes too little or no insulin that is necessary for proper glucose metabolism. Insulin deficiency in the body causes many rapidly progressing biochemical disturbances, including hyperglycaemia, glycosuria, ketosis, metabolic acidosis, disturbances in the transport and tissue consumption of oxygen, hypertonic dehydration or disturbances in the electrolyte exchange [29]. The chronic hyperglycaemia and oxidative stress are responsible for anomalies in the structure and function of tissues in patients with diabetes, which can lead to their damage. The experimental and clinical data have shown that disruption of homeostasis in the diabetes disrupts the transport of ions (sodium, potassium, calcium, phosphorus, magnesium, chloride, sulphur) between the biological fluids and cells (dyselectrolitaemia and transmineralisation) [15].

Metabolic disorders in diabetes are the main causative agents of numerous complications, such as extensive changes in bone tissue mineral metabolism, which leads to delayed bone maturation, affects the linear growth and body structure in people with diabetes [8]. It has been noted that the annual bone loss in patients with type 1 diabetes is $1.35 \%$ [21]. Furthermore, the rate of loss of minerals from bone tissues is significantly higher in patients with a deterioration of glucose metabolism despite the increasing supply of insulin [8].

Numerous studies have been assessing the impact of type 1 diabetes on long bones as mentioned before. There has been much less research on the specific ef- fects of diabetes on craniofacial complex, the development of which is regulated by hormones, nutrients, mechanical forces (such as chewing of food) and local growth factors $[1,11,22]$. Therefore, the aim of the work was to investigate and collect reports on this topic by analysing bibliographic databases of PubMed.

\section{CHANGES IN THE CRANIOFACIAL BONES DEVELOPMENT IN TYPE 1 DIABETES}

In the experimental research on rats with artificially induced diabetes with streptozotocin Giglio and Lama [11] showed a statistically significant reduction of mandibular growth in all dimensions compared with the control group, which in some individuals resulted in deformation of the mandible. The results showed a reduction in growth of symphyseal, coronoid, and alveolar heights, condyloid, angular, and base lengths, and condyloid width for diabetic animals. Mandibular length, height and length of the base were significantly lower in streptozotocin treated rats as compared with the control group. On the other hand no significant differences in the length of symphyseal process, alveolar length and height of the base were found in diabetic and control group [11]. El-Bialy et al. [8] received similar results in clinical trials, investigating boys aged 14-16 years who had been diagnosed with juvenile diabetes at least 5 years before the study. On the basis of height, weight, lateral cephalometry and radiography of the wrist it was found that patients with diabetes had decreased skeletal maturation and linear and angular cephalometric measurements [8]. Studies have shown that type 1 diabetes has a significant impact also on the process of bone remodelling, which is observed during treatments involving the use of mechanical forces within the masticatory system, e.g. in orthodontic treatment. Several mechanisms explaining the revised model of bone remodelling in patients with diabetes have been identified. One of them is the reduction in bone formation due to decreased osteoblast activity or increased osteoblastic cell apoptosis [5]. It is supposed that another factor may be the increased bone resorbing activity. But here the results of the tests are ambiguous, as a decrease in osteoclast activity has also been noted [7].

\section{CHANGES IN THE MINERAL COMPONENT OF TEETH IN TYPE 1 DIABETES}

The observed metabolic disorders in diabetes also cause changes in the mineral content of teeth. It has 
been proved that the high glucose levels in the blood and saliva, diabetic neuropathy, vascular dysfunction and low resistance associated with diabetes could imply abnormalities of the teeth, and their loss [16]. Tsai et al. [27] found that symptoms in the mouth, which may arise as a consequence of diabetes, include toothache, purulent inflammation of apical periodontitis, tooth decay, discoloration, gingivitis, periodontitis, pathological tooth mobility, loss of teeth. Kapp et al. [14] and Taylor et al. [26] proved that these symptoms can appear many years before the onset of the symptoms of diabetes. Alberti and Zimmet [3] believe that patients with asymptomatic diabetes, with strongly marked implications in the oral cavity are the most difficult cases.

The results of studies describing the relationship between diabetes and the frequency and intensity of dental caries are ambiguous [17]. Most authors showed, that in patients with diabetes mellitus the average number of teeth removed due to caries is significantly higher than in the control group, suggesting that the caries in diabetics proceeds much faster and defence reaction from the pulp is weaker, which consequently leads to tooth loss [20]. Proper mineralisation of teeth during their development is an important factor influencing the lack of teeth susceptibility to caries [4]. The majority of studies assessing the level of mineralisation - hypo-mineralisation of hard dental tissues - is carried out in a rat model because of the fact that the teeth of rodents grow steadily, and thus it is possible to examine the impact of various diseases induced during the growth of the animal on their teeth [21]. Obtained in this way results are compared with the results obtained in the control group of rats living under identical conditions, and thus many variables can easily be eliminated that can affect the results of research on people [21]. Numerous research results have showed low concentration of calcium and fluoride in the incisors of rodents after induction of diabetes [1]. Furthermore, there was an increase in calcium and reduction in fluorine concentration in the blood serum [2]. Presumably, the reduction of calcium levels in the structure of the teeth was due to a decrease in ameloblast activity during development of enamel [5]. This is evidenced by the results obtained in the study based on a similar model, which showed that diabetic condition is associated with decreased deposition of calcium in the bone due to generalised decline in metabolic activity in diabetic rats $[1,2]$. Low concentrations of fluoride observed in teeth and blood serum may be due to the incorporation of fluoride into bone. Gutowska et al. [12] obtained similar results for the levels of fluoride, calcium in blood serum and hard tooth tissues in an experiment on rats, in which diabetes was induced artificially by administering the streptozotocin. The authors also evaluated the levels of magnesium in the blood serum and hard tissues of the teeth of rodents. The study showed that the level of magnesium in tooth tissues of rats with type 1 diabetes was significantly higher in comparison with the control group [12]. Magnesium, like calcium, is an important mineral influencing the integrity of the enamel. However, a high concentration of magnesium in tooth tissues is not desired because it stabilises the defective amorphous calcium phosphate and inhibits the formation of the crystalline form of hydroxyapatite, adversely affecting the hardness of the enamel [9]. Therefore, higher content of magnesium in hard tissues of teeth may result in increased susceptibility to demineralisation and caries occurrence. According to the authors, a possible mechanism of change in the elemental composition of teeth is the disorder in ion transport, mainly calcium, due to the increase in glucose levels, oxidative stress associated with hyperglycaemia. In addition, disturbances in ion transport may be caused by an increase in oestradiol concentration, probably due to the influence of calcium ions on P450 aromatase $[5,12]$.

\section{CHANGES IN THE HISTOLOGY OF TOOTH TISSUES IN TYPE 1 DIABETES}

Atar et al. [4] has found on the basis of studies in rodents using an electron microscope that both type 1 and type 2 diabetes in adults (in dams) can have a direct impact on the development of enamel. All the samples of enamel derived from rodents with diabetes have shown a clearly modified ultrastructure, greater in animals with genetically determined diabetes than in the obesity-induced diabetes. There was an irregular arrangement of hydroxyapatite crystals, a change of shape and perforations of enamel prisms. Also important was the fact that after administration of antidiabetic drugs, creation of proper - regular ultrastructure of enamel occurred in those animals. Energy Dispersive X-ray (EDX) analysis also showed a reduction in the amount of calcium and phosphorus in all regions of the enamel formed after the induction of diabetes as compared with the surface of the teeth produced before the commencement of the disease [4]. 
Another major defect of the enamel frequently encountered in primary teeth in children born to mothers with diabetes is hypoplasia. Enamel hypoplasia is a defect of the tooth crown surface caused by disturbance of enamel matrix secretion. Enamel defects can be congenital or acquired. Hypoplasia is a quantitative damage to the enamel consisting in reducing its thickness. It may be in the form of holes, grooves, total or partial lack of enamel on a bigger or smaller area of the crown. In extreme cases, a change of teeth shape occurs because of a thinner layer of enamel, the teeth take on the shape of a cone or cylinder without any points of contact $[10,28]$.

Data from the literature confirm the occurrence of degenerative lesions in the enamel of the incisors of the offspring of rats with induced experimental diabetes [19, 24]. According to Silva-Sousa et al. [25], the severity of hypoplasia identified in the studies was variable and correlated positively with maternal blood glucose level. The experimental group consisted of pregnant rats which were administered or not administered insulin and a control group getting physiological fluid. Enamel defects in the form of whitish fields were confirmed in macroscopic tests in both experimental groups but not in the control group. Mild to severe enamel hypoplasia was observed by scanning electron microscopy [25].

According to Norén [19], the encountered hypoplasia and expanding of the neonatal line in the enamel are associated with hypocalcaemia occurring more frequently in infants of diabetic mothers. However, Silva-Sousa et al. [24] have found that the defects generated on enamel organ are responsible for the formation of hypoplastic enamel in pups of diabetic dams in which diabetes was induced by the administration of alloxan. In order to investigate the mechanism of developmental changes of enamel, the research was conducted in two stages. The first stage was to analyse the enamel organ in the final part of the stage of enamel secretion in light microscopy. The second stage was morphometric analysis of the enamel matrix formed and of the enamel organ in the final phase of the secretion stage. The authors evaluated following parameters: thickness of the enamel matrix, ameloblast height, area of the ameloblast nucleus, ratio of the largest and smallest diameters of the ameloblast nucleus, thickening of the intermediate layer, thickness of the stellate reticulum, and other [24]. In the presented study, light microscopy revealed no significant changes in the appearance of enamel organ in the pups of diabetic dams, except for a single animal. Although these changes occurred in a single case, it is important to emphasize that the animal in question was from the dam that presented the highest blood glucose levels during the experiment, i.e. $911 \mathrm{mg} / 100 \mathrm{~mL}$ on the $15^{\text {th }}$ day after mating. The morphometric analysis revealed thinner enamel matrix in the experimental groups making a thinner layer of enamel, the secretory ameloblasts of pups from diabetic dams were shorter than those of the control group. Additionally the ameloblast nuclei were smaller in pups from diabetic dams and more elongated in pups from insulin-treated diabetic dams than in the other animals studied and the area of the interstitium of the star-shaped reticulum was larger in pups from insulin-treated dams than in the other animals [24].

Observations of the pulp histopathology in the course of type 1 diabetes have so far been very scarce. Russell [23] showed angiopathies and thickened pulp vascular basement membrane, which may affect the response of leukocytes and the transport of components of humoral and cellular responses. Changes in the structure of pulp vessels, including tiny capillaries, cause exacerbation of inflammations that involve anaerobic bacteria due to reduced oxygen supply [6]. Research by llgüy et al. [13] conducted to determine the size of the pulp chambers and the presence of pulpal stones among patients with type 1 diabetes and healthy patients showed no clinically relevant differences between the groups. The study involved healthy and unfilled (intact) first molars of maxilla and mandible in 56 affected patients and in $\mathbf{5 6}$ healthy patients, and the measurements were made on dental periapical radiographs made in parallel technique [13].

\section{CHANGES IN THE MORPHOLOGICAL STRUCTURE OF HUMAN TEETH IN TYPE 1 DIABETES}

Literature analysis revealed morphological disorders also in some clinical cases of patients with type 1 diabetes. Oral screening examinations conducted by Yamunadevi et al. [30] showed a number of changes in the morphology of teeth of patients with diagnosed diabetes mellitus type 1 . Among them the presence of additional (sixth) cusps in the first mandibular molars is worth noting, which the authors found in 7 of 30 patients studied, including in 5 patients midline cusps (tuberculum interlude), located on the 
Table 1. Morphological and histological changes in teeth of experimental and human diabetics - summary

\begin{tabular}{|c|c|}
\hline Experimental diabetes mellitus & Human diabetes mellitus \\
\hline \multicolumn{2}{|l|}{ Changes in the craniofacial bones } \\
\hline Significant reduction of mandibular growth in all dimensions (Giglio et al.) & \multirow{2}{*}{$\begin{array}{l}\text { Decreased skeletal maturation and linear and angular cephalometric } \\
\text { measurements (El-Bialy et al.) }\end{array}$} \\
\hline Reduction in bone formation (Balint et al.) & \\
\hline \multicolumn{2}{|l|}{ Changes in the mineral component of teeth } \\
\hline $\begin{array}{l}\text { Low concentration of calcium and fluoride in the incisors of rodents after } \\
\text { induction of diabetes (Abbassy et al., Gutowska et al.) }\end{array}$ & $\begin{array}{l}\text { Significantly higher average number of teeth removed due to caries } \\
\text { than in the control group, caries proceeds much faster (Ofoego et al.) }\end{array}$ \\
\hline \multicolumn{2}{|l|}{$\begin{array}{l}\text { Significantly higher level of magnesium in tooth tissues of rats with } \\
\text { diabetes mellitus type } 1 \text { (Gutowska et al.) }\end{array}$} \\
\hline \multicolumn{2}{|l|}{ Changes in the histology of tooth tissues } \\
\hline $\begin{array}{l}\text { Modified ultrastructure of enamel, irregular arrangement of hydroxyapatite } \\
\text { crystals, change in shape of prisms (Atar et al.) }\end{array}$ & $\begin{array}{l}\text { Angiopathies and thickened pulp vascular basement membrane } \\
\text { (Russell et al.) }\end{array}$ \\
\hline \multirow{2}{*}{$\begin{array}{l}\text { Occurrence of degenerative lesions (hypoplasia) in the enamel of the incisors } \\
\text { of the offspring of rats with induced experimental diabetes (Norén et al., } \\
\text { Silva-Sousa et al.) }\end{array}$} & Changes in the structure of pulp vessels (Bender et al.) \\
\hline & No significant differences in size of pulp chamber (llgüy et al.) \\
\hline \multicolumn{2}{|l|}{ Changes in the morphological structure of teeth } \\
\hline & $\begin{array}{l}\text { Changes in tooth morphology (e.g. additional cusp) } \\
\text { (Yamunadevi et al.) }\end{array}$ \\
\hline
\end{tabular}

lingual surfaces of molars, and two other cases of the $6^{\text {th }}$ cusps included cusps located on the edge of the marginal distal lower molars (tuberculum sextum). It should be added that the researchers did not find cusps in the above-mentioned additional teeth in the control group. Furthermore, the authors found in the study group one case of an additional $5^{\text {th }}$ and $6^{\text {th }}$ cusp in the lower second molars, the pattern of the letter " $Y$ " on the occlusal surface of the mandibular first premolar, four cusps in the second pre-molar tooth of the lower jaw, lower molar flower-shaped tooth, Carabelli trait in the first molar of the jaw each and 2 cases of mandibular first molar with 4 cusps (which was not considered as anomaly). A few patients were diagnosed with microdontia by the authors of the study. So the information about changes in tooth morphology in diabetic patients is rather limited.

\section{CONCLUSIONS}

Numerous reports confirm that diabetes, especially type 1, as a metabolic disorder may affect changes in the structure of facial skeleton and mineralised dental tissues (Table 1) thereby suggests increasing their susceptibility to caries development and orthognathic disorders. To know this exact mechanism of type 1 diabetes, further studies on larger group of population and advanced researches on odontogenesis should be continued.

\section{REFERENCES}

1. Abbassy MA, Watari I, Soma K (2008) Effect of experimental diabetes on craniofacial growth in rats. Arch Oral Biol, 53: 819-825.

2. Abbassy MA, Watari I, Soma K (2010) The effect of diabetes mellitus on rat mandibular bone formation and microarchitecture. Eur J Oral Sci, 118: 364-369.

3. Alberti KG, Zimmet PZ (1998) Definition, diagnosis and classification of diabetes mellitus and its complications. Part 1: diagnosis and classification of diabetes mellitus provisional report of a WHO consultation. Diabet Med, 15: 539-553.

4. Atar M., Atar-Zwillenberg, Verry P, Spornitz UM (2004) Defective enamel ultrastructure in diabetic rodents. Int J Paed Dent, 14: 301-307.

5. Balint E, Marshall CF, Sprague SM (2001) Glucose-induced inhibition of in vitro bone mineralization. Bone, 28: 21-28.

6. Bender LB, Bender LB (2003) Diabetes mellitus and dental pulp. J Endod, 29: 383-389.

7. Bensch L, Braem M, Van Acker K, Willems G (2003) Orthodontic treatment considerations in patients with diabetes mellitus. Am J Orthod Dentofacial Orthop, 123: 74-78.

8. El-Bialy T, Aboul-Azm SF, El-Sakhawy M (2000) Study of craniofacial morphology and skeletal maturation in juvenile diabetics (type I). Am J Orthod Dentofacial Orthop, 118: 189-195.

9. Fejerskov O, Kidd E (2008) Dental caries. The disease and its clinical management. Wiley-Blackwell.

10. Ghanim A, Elfrink M, Weerheijm K, Marino R, Manton D (2015) A practical method for use in epidemiological studies on enamel hypomineralisation. Eur Arch Peadiatr Dent, 16: 235-246. 
11. Giglio MJ, Lama MA (2001) Effect of experimental diabetes on mandible growth in rats. Eur J Oral Sciences, 109: 193-197.

12. Gutowska I, Baranowska-Bosiacka I, Rybicka M, Noceń I, Dudzińska W, Marchlewicz M, Wiszniewska B, Chlubek D (2011) Changes in the concentration of microelements in the teeth of rats in the final stage of type 1 diabetes, with an absolute lack of insulin. Biol Trace Elem Res, 139: 332-340.

13. Ilgüy D, Ilgüy M, Bayirli G (2004) The size of dental pulp chamber in adult diabetic patients. Oral Health Dent Manag, 3: 38-41.

14. Kapp JM, Boren SA, Yun S, Le Master J (2007) Diabetes and tooth loss in a national sample of dentate adults reporting annual dental visits. Prev Chronic Dis, 4: A59.

15. Maridonneau I, Braguet P, Garay RP (1983) $\mathrm{Na}^{+}, \mathrm{K}^{+}$transport damage induced by oxygen free redicals in human red cell membranes. J Biol Chem, 258: 3107-3113.

16. Moore WJ (1983) The role of sugar in the aetiology of dental caries: sugar and the antiquity of dental caries. J Dent, 11: 189-190.

17. Moore PA, Weynant RJ, Etzel KR, Guggenheimer J, Mongelluzzo MB, Myers DE, Rossie K, Hubert H, Block HM, Orchard T (2001) Type 1 diabetes mellitus and oral health: assessment of coronal and root caries. Comm Dent Oral Epidemiol, 29: 183-194.

18. Nancy A (2014) Ten cate's oral histology: development, structure, and function. Elsevier Health Science, St. Louis.

19. Norén JG (1984) Microscopic study of enamel defects in deciduous teeth of infants of diabetic mother. Acta Odontol Scand, 42: 153-156.

20. Ofoego AN, Obi AU, Ihentuge C, Fawehinmi HB (2013) Abnormalities of the single-rooted anterior teeth: an index for early detection of diabetic patients. Int J Comm Res, 2: 50-56.
21. Ozbek M, Dural S, Kanli A, Tuncel M, Orhan K (2009) Morphological evaluation of rat incisor enamel and dentin induced by pregnancy and lactation using a scanning electron microscope. J Vet Med Sci, 71: 1273-1277.

22. Roe TF, Mora S, Costen G, Kaufman F, Carlson M, Gilsanz V (1991) Vertebral bone density in insulin-dependent diabetic children. Metabolism, 40: 967-971.

23. Russell BG (1967) The dental pulp in diabetes mellitus. Acta Pathol Microbiol Scand, 70: 319-320.

24. Silva-Sousa YT, Peres LC, Foss MC (2003) Are there structural alterations in the enamel organ of offspring of rats with alloxan-induced diabetes mellitus? Braz Dent J, 14: 162-167.

25. Silva-Sousa YT, Peres LC, Foss MC (2003) Enamel hipoplasia in a litter of rats with alloxan-induced diabetes mellitus. Braz Dent J, 14: 87-93.

26. Taylor GW, Burt BA, Becker MP (1996) Severe periodontitis and risk for poor glycemic control in patients with non-insulin-dependent diabetes mellitus. J Periodontol, 67: 1085-1093.

27. Tsai C, Hayes C, Taylor GW (2002) Glycemic control of type 2 diabetes and severe periodontal disease in the US adult population. Comm Dent Oral Epidentol, 39: 182-192.

28. Weerheijm KL (2004) Molar incisor hypomineralization (MIH): clinical presentation, aetiology and management. Dent Update, 31: 9-12.

29. World Health Organization (1999) Definition, diagnosis and classification of diabetes mellitus and its complications. Report of WHO consultation. Part 1. Diagnosis and classification of diabetes mellitus. WHO, Genewa.

30. Yamunadevi A, Basandi PS, Madhushankari GS, DonoghueM, Manjunath A, Selvamani M, Puneeth HK (2014) Morphological alterations in the dentition of type I diabetes mellitus patients. J Pharm Bioallied Sci, 6: 122-126. 